\title{
Hydroponisen rehuntuotannon mahdollisuudet Suomessa
}

\author{
Piia Kekkonen ${ }^{1}$, Kirsi Mäkiniemi ${ }^{1}$, Noora Ruuskanen², Teija Rönkä², Minna Kivimäenpää3 \\ Rosa Mäkeläinen ${ }^{3}$ \\ ${ }^{1}$ Luonnonvara-ala, Savonia-ammattikorkeakoulu, Iisalmi, FINLAND \\ ${ }^{2}$ SeAMK Ruoka, Seinäjoen ammattikorkeakoulu, Seinäjoki, FINLAND \\ ${ }^{3}$ Ympäristö-ja biotieteiden laitos, Itä-Suomen yliopisto, Kuopio, FINLAND
}

\section{TIIVISTELMÄ}

Hydroponisella rehuntuotannolla tarkoitetaan siementen idätystä ja versotusta niin, että siemenistä syntyy kokonaisuudessaan eläimille syötettävä rehumassa tai -matto. Hydrorehu-hankkeessa selvitettiin hydroponisen rehuntuotannon mahdollisuuksia Pohjois-Savon ja Etelä-Pohjanmaan olosuhteissa vuosina 2017-2018. Hankkeessa kokeiltiin ja kehitettiin hydroponista rehuntuotantoa Itä-Suomen yliopiston kasvatuskaapeissa sekä kuudella kotieläintilalla Pohjois-Savossa ja Etelä-Pohjanmaalla tarkoitusta varten vuokratussa siirrettävässä kasvatusdemokontissa.

Kasvatuskokeissa optimaaliseksi kasvatuslämpötilaksi osoittautui $+21{ }^{\circ} \mathrm{C}$. Viljoilla ja herneellä riittävä kasvatusaika kasvatuskontissa oli 7 vrk, kun siemenet esikäsiteltiin vedellä ja liotettiin 4-12 h. Lisäksi havaittiin, että kasteluveden määrä on aina säädettävä kullekin siemenerälle ja kasvatussysteemille erikseen ja että suhteellisen edulliset kasveille tarkoitetut LED-valot soveltuivat hyvin hydroponiseen versonkasvatukseen. Homeet lisääntyivät kasvustoissa nopeasti, mikäli kasvatushuoneen lämpötila nousee korkeaksi ja kosteus on korkea. Optimaalinen tilanne kasvun kannalta on, kun kosteus on 50-60 $\%$ ja huoneistossa on riittävä ilmanvaihto.

Kasvatuksessa kokeiltiin eri lajeja ja lajikkeita. Ohra, kaura ja härkäpapu kasvoivat huonosti ja kasvustoissa oli homeita. Vehnä ja herne kasvoivat hyvin. Tuoresatoa saatiin sekä vehnästä että herneestä keskimäärin 4,5 kg käytettyä siemenkiloa kohti, vaihtelu satomäärissä oli kohtalaisen suurta. Analysoitavaksi lähetettiin näytteitä aistinvaraisesti rehukäyttöön sopiviksi arvioiduista eristä. Salmonellaa ei löydetty ja Escherichia coli -bakteerin pitoisuudet olivat analysoiduissa näytteissä elintarvikekäytössä hyväksyttävänä rajana. Alkuperäiseen siemenmateriaaliin verrattuna versorehun kuiva-aine sisälsi enemmän raakavalkuaista, NDF-kuitua sekä kivennäis- ja hivenaineita, mutta vähemmän solunsisällyshiilihydraatteja. Puhdas kasvusto maittoi eläimille pääasiassa hyvin. Havaittiin, että rehu tulee syöttää nopeasti, sillä se ei kestä varastointia.

Ulkomailla tehtyjen tutkimusten mukaan hydroponinen viljely on hyvin harvoin nähty taloudellisesti kannattavana rehuntuotantomuotona. Hydrorehu-hankkeen demokasvatuksissa havaittiin, että kuivaainehävikki, työkustannukset, energiakustannukset, siemenkustannukset sekä haasteet rehun laadussa tuovat uhkia sekä kustannuksia hydroponisen rehun tuottoon. Mahdollisuudet kasvatuksessa voivat olla esimerkiksi virikerehun tuotannossa tai pieneläinten ja hyönteisten rehuntuotannossa. Sato tuotetaan ympäristöystävällisesti, sillä rehun tuotannossa ei tarvitse käyttää kemiallisia lannoitteita eikä kasvinsuojeluaineita tai muita kemikaaleja, mikäli siemen on hyvälaatuista. Lisätutkimuksia hydroponisesti tuotettujen rehujen merkityksestä kotieläinten hyvinvointiin tarvitaan, jotta saadaan selville hydroponisen tuotannon todellinen kannattavuus.

Asiasanat: vesiviljely, rehu, versorehu 


\section{Johdanto}

Hydroponisesti tuotettu rehu tarkoittaa jyvien tai palkokasvinsiementen idätystä ja versotusta paljaalla kasvatusalustoilla hyödyntäen pelkkää vettä, keinovaloa ja lämpöä. Usein alustat ovat päällekkäin tilan säästämiseksi ja myös veden käyttöä voi säännöstellä. Saman tyyppisiä tekniikoita käytetään puutarhatuotannossa. Rehua tällä menetelmällä tuotetaan lähinnä vaikeista sääolosuhteista kärsivillä alueilla, joilla rehu saatavuus tai sen laatu on osan vuotta heikko.

Hydrorehu-hankkeen tavoitteena oli selvittää tekniset, biologiset ja taloudelliset mahdollisuudet versoväkirehun tuotantoon hydroponisen viljelyn keinoilla Suomessa. Itä-Suomen yliopistolla tehdyissä kasvatuskokeissa pyrittiin selvittämään hydroponisen viljelyn optimiolosuhteet. Nämä kokeet ja tutustuminen hydroponiseen viljelyyn opintomatkalla Liettuassa toimivat pohjana suunniteltaessa siirrettävää kasvatuskonttia, jossa menetelmän toimivuutta testattiin maatilaolosuhteissa Pohjois-Savossa ja Etelä-Pohjanmaalla. Eri kasvilajeja ja -lajikkeita testattiin näissä molemmissa. Tässä tekstissä pääpaino on kasvatuskonttikokeiden tarkastelussa.

\section{Materiaali ja menetelmät}

Itä-Suomen yliopiston kokeet tehtiin kuudessa kasvatuskammiossa. Kammiossa oli LED-valaistus ja automaattinen kastelujärjestelmä suodatetulla vesijohtovedellä. Vettä ei kierrätetty laitteistossa, ja sen pH:ta seurattiin. Suhteellinen ilmankosteus oli 75\% ja kasvatusaika seitsemän vuorokautta. Kokeissa verrattiin kasvatuslämpötiloja $5-25^{\circ} \mathrm{C}$ väliseltä alueelta viiden celsiusasteen välein ja käytetiin kahta erilaista valaistusrytmiä, jotka jäljittelivät touko- ja kesäkuun olosuhteita. Lisäksi verrattiin siementen desinfiointi- ja liotuskäsittelyjä. Sadot punnittiin verso-, juuri- ja siemenmassat eriteltynä ja sadon kuivaainepitoisuus määritetttin (Mäkeläinen 2019).

Maatilakokeissa käytetty kasvatuskontti suunniteltiin yhteistyössä hankkeen toimijoiden kanssa. Laitteiston rakensi eristettyyn eurokonttiin (noin $35 \mathrm{~m}^{2}$ ja $88 \mathrm{~m}^{3}$ ) liettualainen Grainis Agrotech. Kontin eteisessä oli hygieniasulku ja sähköpääkeskus. Varsinaisessa kasvatustilassa oli kaksi yhden kuution vesisäiliötä, automatiikan ohjauskeskus, sekä työskentelytilaa siementen esikäsittelylle. Kontin toisessa päässä ovat kasvatusalustat, joissa oli 3\% kallistus ylimääräisen veden poistamiseksi. Kastelu toimi tulvakasteluna ja laitteisto oli suunniteltu toimimaan siten, että kasteluvettä kierrätettiin pumpuilla. Järjestelmässä oli myös suodattimet. Veden $\mathrm{pH}: t a$ ja johtokykyä seurattiin ohjausyksiköstä. Lämmitys toimi ilmalämpöpumpun avulla. Kontin olosuhteista seurattiin lämpötilaa ja ilman kosteutta; tavoitteena oli noin $21^{\circ} \mathrm{C}$ lämpötila ja $50-60 \%$ ilman kosteus. Kontissa käytettiin valaistuksessa sinisen (449-459 nm) ja punaisen (617-627 nm) aallonpituuden LED-valoja 14,4 W m . Kontissa oli mittarit sähkön ja veden kulutuksen seurantaa varten. Käyttökokemukset kerättiin kyselylomakkeella ja haastattelemalla.

Siemenet molempia kokeita varten hankittiin sekä siemenpakkaamoista että suoraan viljelijöiltä. ItäSuomen yliopiston kokeissa testattiin yhteensä viittä vehnä-, ohra- tai kauralajiketta sekä kahta hernelajiketta. Maatilakokeissa testattiin yhteensä kolmea ohra- tai vehnälajiketta ja kahta hernelajiketta. Osa siemenistä oli luonnonmukaisesti tuotettuja. Siemeniä liotettiin ennen kylvöä hapetetussa vedessä 416 h ja kylvömäärän tavoite oli 4-5 $\mathrm{kg} \mathrm{m}^{-2}$. Kasvatusajaksi tavoiteltiin viljoilla 7 päivää ja herneellä hieman pidempää jaksoa. Ensimmäinen siemenerä (ohra) desinfioitiin natriumhypokloriitilla liettualaisen toimittajan ohjeen mukaan, mutta tämän jälkeen siementen desinfioinnista luovuttiin.

Kasvatuskonttikokeiden sato punnittiin ennen syöttöä. Rehumassan kemiallinen koostumus määritettiin kemiallisilla menetelmillä Seilabin laboratoriossa, ja näytteistä määritettiin kuiva-aine, raakavalkuais, 
raakarasva-, NDF- ja tuhkapitoisuudet. Tärkkelys määritettiin entsymaattisella menetelmällä. Osasta näytteistä analysoitiin myös kivennäis- ja hivenainepitoisuudet. Rehun hygieenistä laatua tutkittiin määrittämällä Salmonella, Escherichia coli ja DON-toksiinit. Tämän lisäksi tehtiin kuiva-aineanalyysejä tilaolosuhteissa.

\section{Tulokset ja tulosten tarkastelu}

Kasvatuskaappikokeissa ilmeni, että $5-10{ }^{\circ} \mathrm{C}$ on selvästi liian matala lämpötila rehun kasvatukseen. Versojen kasvu alkoi osin jo $15^{\circ} \mathrm{C}$ lämpötilassa, mutta versot kasvoivat paremmin $20-25^{\circ} \mathrm{C}$ lämpötilassa. Osassa siemenistä oli punahometta, kasvustot homehtuivat eikä niistä sen takia saatu tuloksia. Tämä oli enemmän viljojen kuin herneen ongelma. Homehtumisriski lisääntyi ylimmässä $25{ }^{\circ} \mathrm{C}$ lämpötilassa ja osassa kasvustosta näkyi myös merkkejä ravinteiden puutteesta. Optimaalisen lämpötilan pääteltiin olevan noin $21{ }^{\circ} \mathrm{C}$. Toukokuun valorytmi osoittautui kasvun kannalta paremmaksi kuin kesäkuun valorytmi. Seitsemän vuorokautta oli herneelle liian luultavasti lyhyt kasvatusaika. Veden pH:n hallinta ja sopivan kastelurytmin löytäminen oli ajoittain haasteellista (Mäkeläinen 2019).

Kasvatuskontin saapumisen jälkeen helmi-maaliskuussa 2018 ulkolämpötila oli alimmillaan noin $-25^{\circ} \mathrm{C}$, mutta toisaalta lämpötila myös vaihteli paljon. Pakkaset aiheuttivat vesiputkien jäätymistä, mutta lämmitys toimi ja kasvatusolosuhteet saatiin pidettyä toivotulla tasolla. Kasvatuksen jatkuivat elokuulle, ja kesällä mitattiin hellelukemia. Kontti lämpeni helteessä, ja myös kontin sisälämpötila nousi tavoitetta korkeammaksi. Tilanteesta selvittiin säätämällä laitteistoa. Valaistus (115 $\left.\mu \mathrm{mol} \mathrm{m}^{-2} \mathrm{~s}^{-1} \mathrm{PAR}\right)$ oli riittävä hydroponiseen kasvatukseen. Teknisesti kontti oli toimiva. Kuukauden kasvatusjaksolla kului vettä 5-9 $\mathrm{m}^{3}$ ja sähköä 760-900 kWh.

Kontin päivittäiseen rutiiniin kuuluu siementen esiliotus, liotettujen siementen kylvö alustoille, valmiiden rehumattojen korjuu, suodattimien ja laitteistojen ylläpitopuhdistus sekä muistiinpanot kasvatusolosuhteista. Viikoittain kalibroitiin $\mathrm{pH}$ - ja sähkönjohtavuusmittarit ja puhdistettiin isoimmat suodattimet kastelujärjestelmästä. Työaikaa kului täydellä kapasiteetilla 1-2 tuntia päivässä. Tästä suurin osa kului siementen kylvämiseen ja sadon korjuuseen. Täydellä kapasiteetilla pystyi kontissa tuottamaan noin $100-150 \mathrm{~kg}$ tuoretta rehua päivässä.

Tiloilla koettiin, että kontti oli helppo ja nopea ottaa käyttöön. Siementen esikäsittely ja kylvö sujui myös hyvin, mutta sadonkorjuu ja siisteyden ylläpito koettiin sekä työlääksi että fyysisesti raskaaksi. Myös ruokinta koettiin työlääksi. Tutkimukseen osallistuneilla tiloilla oli lypsy- ja emolehmiä, pieneläimiä sekä sikoja. Versorehu tarjottiin eläimille erillisruokintana ja rehu maittoi hyvin.

Satotietoja saatiin maatilakokeissa kerättyä tuorekilomäärinä yhteensä 31 koejäsenestä, joista 20 oli vehnästä ja 11 herneestä kasvatettuja. Nämä kasvustot olivat laadultaan silmämääräisesti syöttökelpoisia. Syöntikelvottomat ja pilaantuneet erät jätettiin punnitsematta. Homeiden kasvu aiheutti ongelmia heti, jos laitteiston puhtaanapito jäi huolehtimatta. Myös kastelua ja ilmankosteutta jouduttiin säätämään homeiden kasvun hillitsemiseksi. Tuoresatoa saatiin sekä vehnästä että herneestä keskimäärin 4,5 kg käytettyä siemenkiloa kohti. Vaihtelu oli vehnällä 3-6,3 kg satoa siemenkiloa kohti ja herneellä 2,8-5,4 kg satoa siemenkiloa kohti. Vaihtelua lienee aiheuttanut $\mathrm{mm}$ hieman vaihtelevat kasvatusolosuhteet ja siemenmäärät suhteessa kasvatuspinta-alaan.

Kuiva-ainemäärityksiä tehtiin tilaolosuhteissa vain satunnaisesti eikä kaikkiin satotuloksiin voitu yhdistää kuiva-ainemääritystulosta. Tehtyihin määrityksiin perustuen vehnästä saatiin tilakohtaisesti keskimäärin $0,6-0,8 \mathrm{~kg}$ ka satoa siemen kuiva-ainekiloa kohti. Herneestä saatiin muutama yksittäinen tulos, keskimäärin $0,7-0,8 \mathrm{~kg}$ ka satoa siemen kuiva-ainekiloa kohti. Kuiva-ainehävikkiä syntyy, koska jyvistä voi liueta 
ravintoaineita jo liotusvaiheessa. Itämisvaiheen aineenvaihdunnassa kuluu erityisesti jyvän sisältämää tärkkelystä. Juurien ravinteiden otto ja yhteyttäminen eivät pystyy korvamaan tätä hävikkiä lyhyen kasvatusajan aikana. Sneathin \& McIntoshin (2003) mukaan kuiva-ainehävikki on ollut pienimmillään 7 $9 \%$, mutta usein $15-20 \%$.

Tulokset versorehun kemiallisesta koostumuksesta olivat vaihtelevia (Taulukko 1). Aiemmissa tutkimuksissa on todettu, että versorehun koostumus muuttuu kasvun edetessä (Peer ja Leeson 1985, Naik ym. 2015). Näytteitä on saatettu kerätä tiloilla hieman eri vaiheissa kasvua. Kasvava massa on myös heterogeenista, ja edustavan näytteen otto voi olla haastavaa. Kuiva-ainepitoisuus oli versorehussa matala, ja vastaava kuin aiemmissa tutkimuksissa (Sneath ja McIntosh 2003, Soder ym. 2018). Raakavalkuaispitoisuus oli korkea, erityisesti herneestä kasvatetussa rehussa. Entsymaattisen tärkkelysanalyysin antamat tulokset olivat hyvin vaihtelevia. Tämä johtuu todennäköisesti siitä, että kasvatusprosessin aikaan tärkkelys hajoaa sokereiksi, ja analyysin tärkkelystulos lasketaan näytteestä määritetyn sokeripitoisuuden perusteella. Tämän vuoksi laskettiin myöhemmin solunsisällyshiilihydraattien pitoisuus käyttäen hyväksi muita analyysituloksia.

Taulukko 1. Versorehun kemiallinen koostumus keskimäärin ja tulosten vaihteluväli

\begin{tabular}{lccc}
\hline & Vehnä $(\mathrm{n}=10)$ & Herne $(\mathrm{n}=8)$ & Ohra $(\mathrm{n}=2)$ \\
\hline Kuiva-aine $\mathrm{g} \mathrm{kg}^{-1}$ & 143 & 134 & 134 \\
& $(101-228)$ & $(80-185)$ & $(121-146)$ \\
Raakavalkuainen $\mathrm{g} \mathrm{kg}^{-1} \mathrm{ka}$ & 199 & 362 & 188 \\
& $(140-240)$ & $(292-450)$ & $(185-190)$ \\
Solunsisällyshiilihydraatit, g kg-1 ka & 439 & 235 & 401 \\
& $(371-525)$ & $(75-296)$ & $(393-408)$ \\
NDF g kg-1 ka & 321 & 350 & 356 \\
& $(274-380)$ & $(329-388)$ & $(352-360)$ \\
Tuhka, $\mathrm{kg}^{-1} \mathrm{ka}$ & & & 41,5 \\
& $(21-32)$ & $(39-63)$ & $(41-42)$ \\
\hline
\end{tabular}

Alkuperäiseen siemenmateriaaliin verrattuna versorehu sisältää enemmän raakavalkuaista, NDF-kuitua sekä kivennäis- ja hivenaineita, mutta vähemmän solunsisällyshiilihydraatteja (Taulukko 2). Vastaavia tuloksia on saatu myös aiemmissa tutkimuksissa (Peer ja Leeson 1985, Sköldberg 1991), ja selityksenä muutoksille pidetään tärkkelyksen kulumista itämisprosessin aikana. Tämän seurauksena muiden ravintoaineiden suhteelliset osuudet kasvavat. Ohrasta saatuja tuloksia tarkastaessa on hyvä huomioida, että ohrakasvustoja oli lannoitettu liettualaisen laitetoimittajan ohjeiden mukaisesti. Lannoitusta ei enää myöhemmin jatkettu.

Taulukko 2. Versorehun ja käytetyn siemenmateriaaliin koostumuksen vertailu.

\begin{tabular}{lcccc}
\hline Koostumus $\mathrm{g} \mathrm{kg}^{-1} \mathrm{ka}$ & \multicolumn{2}{c}{ Amaretto-vehnä $(\mathrm{n}=5)$} & \multicolumn{2}{c}{ Wolmari-ohra $(\mathrm{n}=2)$} \\
\hline & Versorehu & Siemen & Versorehu & Siemen \\
Raakavalkuainen & 195 & 135 & 193 & 108 \\
Solunsisällyshiilihydraatit & 441 & 723 & 401 & 643 \\
NDF & 325 & 107 & 356 & 207 \\
Tuhka & 26 & 19 & 42 & 23 \\
\hline
\end{tabular}


Vaikka versorehu onkin käytettyä siemenerää valkuaispitoisempaa, ei raakavalkuaisen kokonaismäärä kuiva-ainehävikin takia kuitenkaan yleensä lisäänny. Hankkeen tulokset kuiva-ainesadoista olivat liian epävarmoja ja koostumusnäytteitä vähän tämän asian analysoimiseksi.

Kivennäisanalyysien tuloksista voi todeta, että versorehun kalsium- ja magnesiumpitoisuudet ovat suhteellisen matalia, kun taas fosforipitoisuus on korkeampi kuin karkearehuilla yleensä. Kaliumpitoisuus on erityisesti viljoista kasvatetuissa versorehuissa matala (Taulukko 3).

Taulukko 3. Versorehun kivennäisainepitoisuus $\mathrm{g} \mathrm{kg}^{-1} \mathrm{ka}$

\begin{tabular}{lcccc}
\hline & $\mathrm{Ca}(\mathrm{n}=20)$ & $\mathrm{P}(\mathrm{n}=18)$ & $\mathrm{Mg}(\mathrm{n}=13)$ & $\mathrm{K}(\mathrm{n}=20)$ \\
\hline Ohra $(\mathrm{n}=2)$ & $2-2,3$ & $4,1-4,8$ & $1,2-1,4$ & $5,4-5,8$ \\
Herne $(\mathrm{n}=5-8)$ & $1,1-2,1$ & $5,2-6,7$ & $1,4-1,7$ & $12,5-16,7$ \\
Vehnä $(\mathrm{n}=6-10)$ & $0,5-1,8$ & $5,2-5,8$ & $1,7-2,2$ & $4,6-7,1$ \\
\hline
\end{tabular}

Salmonellaa ei löydetty siemenistä tai versorehusta kummastakaan. Escherichia coli pitoisuudet (n=4) olivat kahdessa versorehunäytteessä alle $10 \mathrm{pmy} \mathrm{g}^{-1}$, mikä on luokiteltu hyväksi tasoksi elintarvikkeille. Kahden tämän tason ylittäneen versorehunäytteen pitoisuudet sijoittuivat luokkaan alle 100 pmy g $^{-1}$, kun elintarvikekäytössä hyväksyttävänä pidetään alle $500 \mathrm{pmy} \mathrm{g}^{-1}$ tuloksia. DON-toksiineja ei löytynyt käytetyistä siemeneristä, mutta ohrasta kasvatetuissa versorehuissa oli silmämääräisesti hyvästä laadusta ja siemenen desinfioinnista huolimatta 1000-1500 $\mu \mathrm{g}$ DON-toksiineja $\mathrm{kg}^{-1}$ rehua kaikissa kolmessa otetussa näytteessä. Kyseisen ohraerän yleisenä ongelmana oli homehtuminen kasvatuksen aikana ilman siemenen desinfiointia. Vehnästä kasvatetuista versorehuista löytyi DON-toksiineja kahdesta näytteestä viidestä, 50 ja $850 \mu \mathrm{g} \mathrm{kg}^{-1}$. Kasvatuskaappikokeiluista otetuista näytteistä mitattiin enimmillään $5500 \mu \mathrm{g} \mathrm{kg}^{-1} \mathrm{DON}$ toksiinipitoisuuksia. Toisaalta EU:n viljalle ja viljatuotteille antama suositus alle $8 \mathrm{mg}$ DON-toksiineja kuivaa viljakiloa kohti (EY/2006/576) alittuu vielä selvästi.

\section{Johtopäätökset}

Hygieeniselta laadultaan hyvä ja itävä siemen, kasvatuslaitteiston hygienian ylläpito sekä olosuhteiden hallinta ovat menetelmän onnistumisen ehdottomia edellytyksiä. Jos näissä epäonnistutaan, homeet lisääntyvät, rehun kasvun heikkenee ja rehuhävikki kasvaa. Homeiden muodostavat toksiinit voivat alentaa eläinten tuotosta ja jopa aiheuttaa eläinten kuolemia. (Sneath ja McIntosh 2003). Hankkeessa käytetyillä kasvoivat parhaiten herne ja vehnä, joilla homeen kasvu aiheutti vähiten ongelmia. Liotusveteen on kokeiltu lisätä homeiden kasvua estäviä tai hidastavia kemikaaleja, tai siemenet voidaan liotuksen jälkeen huuhdella desinfiointiliuoksella. Desinfiointiaineiden käytössä on kuitenkin huomioitava rehulainsäädäntö ja kemikaalien hävittämistä koskevat ohjeet. Mikään esimerkiksi kasvatuskaappikokeissa (Mäkeläinen 2019) kokeilluista desinfiointiaineista (natriumhypokloriitti, peretikkahappo tai Virkon S) ei sovellu rehukäyttöön. Hankkeen aikana vierailtiin liettualaisella tilalla, jossa siementen hygienisointiin käytettiin elektrolysoitua vettä, joka valmistettiin ruokasuolaliuoksesta. Menetelmää on kokeiltu elintarvikkeeksi käytettävien itujen käsittelyssä, ja sitä varten tarvitaan erillinen laite (Sikin ym. 2013). Sertifioidun siemenen käyttö pienentää siemenmateriaaliin liittyvää riskiä, mutta lisää kustannuksia.

Suurimmat kustannuserät rehun tuotannossa ovat siementen lisäksi työ- ja energiakustannukset. Tuotantoon liittyvät riskit ja kuiva-ainehävikki kasvatuksen aikana ovat myös merkittäviä kustannustekijöitä. Kasvatus on yleensä suuremmassakin mittakaavassa paljon työtä vaativaa, koska kylvöä ja sadonkorjuuta ei ole helppo automatisoida. Kasvatuslaitteisto voi vaatia suuria investointeja, joiden takaisinmaksuaika on pitkä (Soder ym. 2018). Ruokintatyötä voidaan vähentää käyttämällä seosrehuruokintaa. Versorehun osuus 
ruokinnassa jää työlään kasvatusprosessin takia käytännössä pieneksi. Kontrolloiduissa tutkimuksissa, joissa rehujen kulutus ja eläinten tuotos on mitattu, versorehu ei yleensä ole lisännyt tuotosta (Sneath ja McIntosh 2003). Tuotoslisäys on todennäköisin, kun versorehua käytetään määrällisesti niukan tai sulavuudeltaan huonohkon perusruokinnan lisänä (Rodriguez-Muela ym. 2005, Naik ym. 2015). Käyttö tuotantoeläimille ei Suomen olosuhteissa ole todennäköistä. Mahdollisesti versorehua voisi tuottaa pienimuotoisesti, esimerkiksi virikerehuksi tai pieneläimille.

\section{Kiitokset}

Kiitämme rahoittajaa ELY-Keskusta ja Maaseudun kehittämisen rahastoa sekä maatiloja demokasvatukseen osallistumisesta. Kiitos työkavereille avusta ongelmanratkaisussa sekä alueen tuottajille siemenmateriaalin sekä kokemusten jakamisesta.

\section{Lähteet}

EY/2006/576. Komission suositus deoksinivalenolin, zearalenonin, okratoksiini A:n, T-2- ja HT-2-toksiinin sekä fumonisiinien esiintymisestä eläinten rehuksi tarkoitetuissa tuotteissa. https://eur-lex.europa.eu/legalcontent/FI/TXT/PDF/?uri=CELEX:32006H0576\&qid=1581085996258\&from=FI

Mäkeläinen, R. 2019. Hydroponisen viljelymenetelmän testaus suomalaisilla viljoilla ja herneillä kasvatusolosuhteiden ja esikäsittelyn optimointi. Viitattu 6.2.2020 https://hydrorehu.savonia.fi/images/pdf/Hydrorehu_Projektityö_RosaMäkeläinen.pdf

Naik P.K., Swain, P.K. \& Singh, N.P. 2015. Production and Utilisation of Hydroponics Fodder. Review. Indian Journal of Animal Nutrition 32: 1-9.

Peer, D.J. \& Leeson, S.1985. Nutrient content of hydroponically sprouted barley. Animal Feed Science and Technology 13: 191-202. https://doi.org/10.1016/0377-8401(85)90022-7

Rodriguez-Muela, C., Rodriguez, H.E., Ruiz, O., Flores, A., Grado, J.A. \& Arzola, C. 2005. Use of green fodder produced in hydroponics systems as supplement for Salers lactating cows during the dry season. Proceedings Western Section, American Society of animal Science 56: 271-274.

https://www.researchgate.net/publication/253685663_Use_of_green_fodder_produced_in_hydroponics_systems_as _supplement_for_salers_lactating_cows_during_the_dry_season/link/5536af5b0cf268fd00187408/download

Sikin, A.M., Zoellner, C. \& Rizvi, S.H.S. 2013. Review: Current Intervention Strategies for the Microbial Safety of Sprouts. Journal of Food Protection 76: 2099-2123. https://doi.org/10.4315/0362-028X.JFP-12-437

Sköldberg, B. 1991. Korngräs i klimatkammare -produktion och fodervärde. Examensarbete, försöksavdelningen för norrlänsk husdjurskötsel. Röbacksdalen meedelar nr3/91.

Sneath, R \& McIntosh, F, 2003. Review of hydroponic fodder production for beef cattle. Meat\&Livestock Austaralia Limited. http://www.royeshgar.com/wp-content/uploads/2016/02/Royeshgar_Hydroponicfodder.pdf

Soder, K.J, Heins, B.J., Chester-Jones, H., Hafla, A.N. \& Rubano, M.D. 2018. Evaluation of fodder production systems for organic dairy farms. The Professional Animal Scientist 34:75-83. https://doi.org/10.15232/pas.201701676 